\title{
Metafora Konseptual Bertema Rihlah (Jalan-Jalan) pada Majalah Gontor: Analisis Semantik Kognitif
}

\author{
Conceptual Metaphors in Traveling Theme on Gontor Magazine: Cognitive Semantic \\ Analysis
}

\author{
Trian Ramadhan Nuryadin ${ }^{1, *}$ dan Tajudin Nur ${ }^{2}$ \\ ${ }^{1,2}$ Magister Linguistik, Fakultas Ilmu Budaya \\ Universitas Padjadjaran \\ 1,*Correspondence email: trianrn33@gmail.com \\ 2Email: tajudin.nur@unpad.ac.id
}

\begin{abstract}
This research is a cognitive semantic analysis and uses descriptive qualitative methods. The problems discussed in this study are the types of conceptual metaphors, namely (1) structural metaphors, (2) orientational metaphors, (3) metaphors. The theory used is the conceptual metaphor from Lakoff \& Johnson (2003) as the main theory and the image scheme from Cruse \& Croft (2004) theory. The data is taken from the Gontor magazine with the theme of "rihlah" (traveling). Based on the analysis conducted, 11 conceptual metaphor data were found, with the following details: seven structural metaphors are the concepts of the meaning of decoration, protection, limb, the taste of food, expenditure, nature, and fame; one orientational metaphor with the concept of the meaning of quality; and three ontological metaphors with the concept of well-known meaning, heredity, and quality of goods. The image schemes found were one power/control scheme, two existence/process schemes, two identity/conformity schemes, and six existence/object schemes.
\end{abstract}

Keywords: metaphor, conseptual, semantic, image scheme

\begin{abstract}
Abstrak: Penelitian ini merupakan suatu analisis semantik kognitif dan menggunakan metode kualitatif yang bersifat deskriptif. Masalah yang dibahas dalam penelitian ini adalah jenis-jenis metafora konseptual, yaitu (1) metafora struktural, (2) metafora orientasional, (3) metafora. Teori yang digunakan adalah metafora konseptual dari Lakoff \& Johnson (2003) sebagai teori utama dan skema citra dari teori Cruse \& Croft (2004). Data diambil dari majalah Gontor bertema rihlah (jalan-jalan). Berdasarkan analisis yang dilakukan ditemukan sebanyak 11 data metafora konseptual, dengan rincian sebagai berikut. Tujuh metafora struktural konsep makna hiasan, pelindung, dahan, rasa makanan, pengeluaran, sifat, dan terkenal. Satu metafora orientasional dengan konsep makna kualitas. Tiga metafora ontologis dengan konsep makna terkenal, turun temurun, dan kualitas barang. Skema citra yang ditemukan sebanyak 1 skema kekuatan/pengendalian, 2 skema keberadaan/proses, 2 skema identitas/kesesuaian, dan 6 skema keberadaan/objek.
\end{abstract}

Kata kunci: metafora, makna konseptual, semantik, skema citra

To cite this article:

Nuryadin, T. R., \& Nur, T. (2021). Metafora Konseptual Bertema Rihlah (Jalan-Jalan) pada Majalah Gontor: Analisis Semantik Kognitif. Diglosia: Jurnal Kajian Bahasa, Sastra, dan Pengajarannya, 4(1), 91-100.

https://doi.org/10.30872/diglosia.v4i1.72 


\section{A. PENDAHULUAN}

Kajian linguistik tidak hanya berfokus pada bunyi atau tata bahasa saja. Namun, pemaknaan terhadap bahasa itu sendiri juga menjadi bahan kajian linguistik. Kajian mengenai makna ini erat kaitannya dengan wacana sebagai bagian dari linguistik. Kosakata dalam suatu bahasa memiliki makna tersendiri dengan kosakata yang lainnya, misalnya kata makan yang berbeda maknanya dengan kata menang. Kosakata beserta pemaknaannya ini lahir dari kesepakatan para penutur bahasa itu sendiri. Apabila sekelompok penutur bahasa sepakat memaknai suatu kata, maka kata itu digunakan secara aktif dalam praktik komunikasi kelompok penutur bahasa tersebut. Pemaknaan terhadap suatu kata tidak bisa dilakukan manasuka agar tidak menimbulkan kesalahpahaman antarpenuturnya.

Semantik yang semula berasal dari bahasa Yunani, mengandung makna to signify atau memaknai. Sebagai istilah teknis, semantik mengandung pengertian "studi tentang makna". Dengan anggapan bahwa makna menjadi bagian dari bahasa, maka semantik merupakan bagian dari linguistik. Seperti halnya bunyi dan tata bahasa, komponen makna dalam hal ini juga menduduki tingkatan tertentu. Apabila komponen bunyi umumnya menduduki tingkat pertama, tata bahasa pada tingkat kedua, maka komponen makna menduduki tingkatan paling akhir (Palmer dalam Aminudin, 2015, hal. 15).

Bahasa dan manusia merupakan dua unsur yang tidak dapat dipisahkan, karenanya bahasa menjadi unsur yang peting dalam kehidupan guna berkomunikasi antar sesama manusia dan makhluk hidup, baik dalam ragam tulisan dan ragam lisan. Pernyataan tersebut sangat sejalan dengan Chaer \& Agustina (2010) bahwa bahasa merupakan alat komunikasi atau alat interaksi yang hanya dimiliki oleh manusia. Tanpa bahasa, manusia akan sangat sulit untuk berkomunikasi dengan makhluk lainnya. Fungsi bahasa dijelaskan oleh Keraf (1994) dalam (Subhan, Nur, \& Nugraha, 2019) yang mengungkapkan empat poin utama yakni sebagai alat ekspresi diri, alat untuk berkomunikasi, sebagai alat untuk mengadakan integrasi dan adaptasi sosial dan sebagai alat untuk mengadakan kontrol sosial. Hal ini sejalan dengan kebutuhan manusia akan manfaatnya bahasa yakni mempersatukan dan menyamakan paham untuk berkomunikasi baik verbal maupun nonverbal yang bersifat arbitrer (manasuka) dan konvensional.

Membaca merupakan kebutuhan bagi manusia agar dapat mengapai informasi yang diperlukan. Berita di media massa, majalah atau pun dalam jejaring sosial daring menjadi kebudayaan dan kebutuhan manusia sebagai makhluk hidup untuk menggapai informasi terbaru dan hangat. Penggunaan metafora dalam penulisannya adalah teknik penulisan agar bagaimana pembaca berita tersebut tak hanya mendapat informasi yang informatif namun dapat membaca bacaan yang menarik dan tidak monoton. Penulis berita ataupun artikel dalam majalah secara langsung ataupun tidak langsung menggunakan metafora sebagai efek perbandingan suatu konsep. Menganalisis makna konseptual dalam wacana yang mengandung metafora di dalamnya sangat menarik dilakukan guna mengungkap suatu maksud penulis. Misalnya, ungkapan "sajian gulai jengkol dan sajian sambalnya cukup menggoda di restoran ini". Kata menggoda selalu digunakan sebagai ajakan atau menarik hati agar berbuat jahat atau dosa. Namun dalam ungkapan tersebut kata "menggoda" dipinjam agar memiliki arti dan sifat yang sexy, yaitu makanan yang begitu lezat sampai dapat menarik hati seseorang untuk melirik dan makan makanan tersebut. 
Semantik merupakan salah satu cabang ilmu dari ilmu linguistik. Semantik telah dipahami sebagai istilah yang digunakan untuk bidang linguistik yang mempelajari tentang tanda-tanda linguistik dengan hal-hal yang ditandainya (Dessiliona \& Nur, 2018). Maka darinya, kata semantik dapat diartikan sebagai ilmu tentang makna atau tentang arti, yaitu salah satu dari tiga tataran analisis bahasa: fonologi, gramatika, dan semantik (Chaer, 2007, hal. 284).

Semantik kognitif merupakan pendekatan berdasarkan eksperimental, yaitu bagaimana bahasa digunakan dan dialami senyatanya (Arimi, 2015, hal. 5). Prinsip analisis semantik kognitif menurut Evans \& Green (2006) berupa pembentukan konsep, struktur semantik, representasi makna, dan pembentukan makna (Wiradharma \& Tharik WS, 2016, hal. 9). Semantik kognitif menyelidiki hubungan antara pengalaman, sistem konseptual, dan struktur semantik yang diwujudkan oleh bahasa. Secara khusus, penganut semantik kognitif menyelidiki struktur konseptual (representasi pengetahuan) dan konseptualisasi (makna konstruksi).

Semantik kognitif merupakan bagian dari linguistik kognitif. Linguistik kognitif menurut Evans \& Green (2006) adalah studi yang mempelajari bagaimana seseorang berpikir akan sesuatu yang diujarkan melalui bahasanya. Definisi tersebut selaras dengan pendapat Cuyckens \& Geeraets (2012) bahwa linguistik kognitif merupakan hubungan antara bahasa dengan fungsi kognisi seseorang. Kognisi setiap orang digunakan untuk mengetahui dan mempelajari segala sesuatu yang ada di dunia ini. Oleh karena itu, setiap konsep yang ada di dunia dapat dimaknai secara kognitif oleh seseorang dan konsep tersebut dapat berbeda karena dipengaruhi oleh budaya yang berbeda-beda (Haula \& Nur, 2019).

Menurut Parera (2004), dalam metafora terjadi pergeseran makna dari dua hal yang dibandingkan dan terkait dengan pengalaman. Buku Metaphor We Live By pada tahun 1980 yang ditulis oleh George Lakoff bersama dengan koleganya, Mark Johnson, membuat banyaknya linguis mengembangkan dan awal dari berkembangnya konsep metafora. Menurut Lakoff \& Johnson (2003, hal. 10-32), metafora adalah sebuah hal yang memiliki makna lain dan fungsi utamanya yaitu untuk memahami. Dapat diartikan bahwa metafora adalah bagian dari bahasa figuratif yang membandingkan satu hal dengan hal yang lainnya. Mereka mengamati bahwa semua bahasa manusia menggunakan makna metafora untuk berkomunikasi pada tingkatan di berbagai abstraksi dari realitas konkret. Teori ini merupakan teori metafora Lakoff \& Johnson yang lebih dikenal dengan teori metafora konseptual.

Pada penelitian ini, penulis memilih majalah Gontor untuk diteliti. Gontor adalah nama pondok pesantren modern yang terletak di Ponorogo Jawa Timur. Majalah Gontor mulai terbit pada tahun 1995, dengan moto "Media Perekat Umat" majalah Gontor mulai mempublikasikan hasil tulisan para jurnalis mulai dari tulisan santri, ustad, sampai dengan umum. Majalah Gontor dipilih oleh penulis karena majalah ini telah banyak dikirim dan dipublikasikan ke seluruh Indonesia. Terdapat berbagai segmen di dalamnya, salah satunya adalah segmen rihlah atau jalan-jalan. Segmen rihlah atau jalan-jalan dipilih karena banyaknya metafora yang digunakan untuk menggambarkan betapa indahnya destinasi wisata yang ditulis dalam artikel tersebut. Segmen rihlah atau jalan-jalan digunakan sebagai sumber data karena ditemukan penggunaan fenomena metafora yang dihubungkan dengan emosi pembaca. Penelitian ini juga berfokus pada jenis-jenis metafora dan skema citra yang terdapat pada wacana artikel tersebut. 
Metafora konseptual yang dikemukakan oleh Lakoff \& Johnson (2003) merupakan hasil dari konstruksi mental berdasarkan prinsip analogi yang melibatkan konseptualisasi suatu unsur pada unsur yang lain. Metafora konseptual mencakup transfer dari ranah sumber (source domain) ke ranah sasaran (target domain) sehingga ranah kedua dipahami tidak terlepas dari ranah pertama. Teori metafora ini lebih dikenal dengan teori metafora konseptual (Conceptual Metaphor Theory/CMT). Ciri penting dari CMT adalah pemanfaatan aspek tertentu dari ranah sumber atau ranah sasaran yang berperan pada metafora. Artinya, jika disarankan bahwa metafora konseptual dapat dinyatakan dengan $Y$ adalah $X$, ini tidak berarti bahwa seluruh konsep $\mathrm{Y}$ atau $\mathrm{X}$ tercakup yang dipilih hanyalah aspek tertentu.

Sebagai contoh, dalam kehidupan sehari-hari kita sering berselisih pendapat dengan orang lain. Ketika terjadi selisih pendapat atau beradu argumen, tentunya masing-masing pihak mempertahankan argumennya. Namun, dalam beradu argumen, tentu saja ada pihak yang kalah dan ada pihak yang menang, meskipun pihak yang menang tersebut belum tentu memiliki argumen yang benar. Berdasarkan pengalaman berargumen tersebut, muncul istilah I don't want to lose my argument (saya tidak mau kalah dalam perdebatan ini) dan I won my argument (saya menang dalam perdebatan ini). Kemenangan dan kekalahan dalam perdebatan atau beradu argumen ini dianggap seperti sedang menghadapi peperangan. Hal tersebut menghasilkan konsep metaforis dalam pikiran manusia bahwa argument is war. Konsep tersebut merupakan pangkal munculnya istilah-istilah metafora lain, seperti dalam kalimat berikut: He shot down all of my argument (Dia menembak seluruh argumen saya) dan I demolished his argument (Saya meruntuhkan argumennya). Kata shot dan demolished merupakan bagian dari konsep war (peperangan), di mana pelaku dalam peperangan saling menembak dan meruntuhkan pertahanan. Berdasarkan contoh tersebut, konsep argument dapat dipahami dan dibentuk melalui konsep war (Lakoff \& Johnson, 2003, hal. 10-32). Dari semua contoh yang diberikan oleh Lakoff \& Johnson (2003) mengenai konsep argument dan war, dapat dipahami bahwa manusia mengamati dan memperlakukan berbagai hal yang mereka jumpai, apa yang mereka rasakan diaplikasikannya dalam bentuk bahasa yang bersifat metaforis lewat tuturan mereka sehari-hari.

Dalam konsep ini terdapat dua ranah konseptual, yaitu ranah sumber dan ranah sasaran. Ranah sumber digunakan manusia untuk memahami konsep abstrak dalam ranah sasaran. Ranah sumber umumnya berupa hal-hal yang biasa ditemukan dalam kehidupan sehari-hari. Ranah sumber lebih bersifat konkret, sedangkan ranah sasaran bersifat abstrak. Metafora mengorganisasi hubungan antarobjek dan menciptakan pemahaman mengenai objek tertentu melalui pemahaman mengenai objek lain. Dengan kata lain, ranah sumber digunakan manusia untuk memahami konsep abstrak dalam ranah sasaran (target domain) metafora konseptual memiliki tiga komponen yakni, ranah sumber (source domain), ranah sasaran (target domain) dan pemetaan (correspondence or mapping) (Lyra, 2018).

Metafora menurut Lakoff \& Johnson (2003) terdiri atas tiga jenis, yaitu metafora struktural, metafora orientasional, dan metafora ontologis. Metafora struktural yaitu sebuah konsep dibentuk secara metaforis dengan menggunakan konsep yang lain. Metafora struktural ini didasarkan pada dua ranah, yaitu ranah sumber dan ranah sasaran. Metafora struktural berdasar pada korelasi sistematis dalam pengalaman sehari-hari. 
Metafora orientasional yaitu metafora yang berhubungan dengan orientasi ruang, seperti naik-turun, dalam-luar, depan-belakang, dan lain-lain. Orientasi ruang ini muncul dari kenyataan bahwa kita memiliki tubuh dan tubuh berfungsi dalam lingkungan fisik. Metafora ini lebih didasarkan pada pengalaman fisik manusia dalam mengatur orientasi arah dalam kehidupan sehari-hari, seperti updown yang diukur dari pengalaman fisik manusia. Metafora orientasional merefleksikan konsep spasial yang berbeda-beda menurut pengalaman fisik atau budaya masyarakatnya (Lakoff \& Johnson, 2003). Oleh karena itu, metafora orientasional berbeda di setiap budaya, karena apa yang dipikirkan, dialami, dilakukan oleh seseorang yang dibesarkan dalam budaya yang berbeda. Metafora orientasional memberikan pada sebuah konsep suatu orientasi ruang, misalnya: happy is up, health is up.

Metafora ontologis adalah metafora yang melihat kejadian, aktivitas emosi, dan ide sebagai entitas dan substansi. Misalnya dalam metafora the mind is a machine dalam kalimat My mind just isn't operating today (Hari ini otak saya tidak bekerja atau hari ini saya sedang tidak ingin berpikir). Metafora ontologis adalah metafora yang mengonseptualisasikan pikiran, pengalaman, dan proses hal abstrak ke sesuatu yang memiliki sifat fisik. Dengan kata lain, metafora ontologis menganggap nomina abstrak sebagai nomina konkret (Lakoff \& Johnson, 2003).

Selain jenis-jenis metafora konseptual, terdapat pula skema citra yang terbentuk dari suatu metafora. Menurut Saeed (2003, hal. 366) skema citra merupakan bentuk penting dari struktur konseptual semantik kognitif. Selain itu, skema citra merupakan struktur makna yang didapat dari pengalaman yang dihasilkan dari bagaimana tubuh berinteraksi dengan dunia. Pengalaman ini berguna untuk pemahaman secara abstrak dan pemahaman terhadap kebernalaran (Dessiliona \& Nur, 2018). Skema citra dapat dikatakan sebagai kerangka mental tak sadar dari bentuk, tindakan, dimensi, dan seterusnya yang terus berulang dan berasal dari persepsi dan perasaan (Haula \& Nur, 2019; Lyra, 2018). Skema citra menurut Cruse \& Croft (2004) terbagi atas tujuh bagian yang terdapat pada Tabel 1 .

Pada penelitian sebelumnya banyak peneliti meneliti data berupa bait puisi dan karya sastra, di mana metafora banyak bersarang. Dalam penelitian ini peneliti menggunakan data berupa artikel dari sebuah majalah yang telah dipilih, di mana metafora jarang digunakan namun peneliti mengambil segmen yang banyak menggunakan metafora, salah satunya adalah segmen jalan-jalan. Selain penulis berharap penelitian ini memiliki kebermanfaatan sebagai penguat teori yang sudah ada khususnya pada metafora konseptual.

Tabel 1. Skema Citra Menurut Cruse \& Croft

\begin{tabular}{ll}
\hline Space & Up-Down, Front-Back, Left-Right, Near-far, CenterPeriphery, Contact \\
\hline Scale & Path \\
\hline Container & Containment, In-Out, Surface, Full-Empty, Content \\
\hline Force & $\begin{array}{l}\text { Balance, Counterforce, Compulsion, Restraint, Enablement, Blockage, Diversion, } \\
\text { Attraction }\end{array}$ \\
\hline Unity/Multiplicity & Merging, Collection, Splitting, Iteration, PartWhole, Mass-Count, Link \\
\hline Identity & Matching, Superimposition \\
\hline Excistence & Removal, Bounded Space, Cycle, Object, Process \\
\hline
\end{tabular}




\section{B. METODE}

Penelitian ini merupakan penelitian kualitatif yang bersifat analisis deskriptif. Menurut Sugiyono (2016) penelitian kualitatif adalah penelitian yang lebih menekankan pada informasi dan data yang terkumpul berbentuk dalam kata-kata atau gambar sehingga tidak menekankan pada angka. Hal ini senada dengan pendapat (Moleong, 2016) bahwa penelitian kualitatif adalah penelitian yang bermaksud untuk memahami fenomena tentang apa yang dialami oleh subjek penelitian secara holistik, dan dengan cara deskripsi dalam bentuk kata-kata dan bahasa, pada suatu konteks khusus dan metode yang alamiah. Penelitian ini mendeskripsikan data yang mengandung ungkapan metaforis. Jenis data penelitian ini adalah data tulis. Data dan sumber data dalam penelitian ini adalah semua data yang mengandung ungkapan metaforis dalam majalah Gontor segmen Rihlah (jalanjalan) tahun 2014, yaitu opini yang terbit pada bulan Maret 2014. Jumlah judul artikel yang dijadikan data sebanyak 2 artikel.

Dalam pengumpulan data, metode yang digunakan adalah metode simak yang dilanjutkan teknik catat. Metode simak metode yang dilakukan dengan menyimak, yaitu menyimak penggunaan bahasa (Sudaryanto, 2015). Dalam pengumpulan data ini, objek yang disimak adalah semua tulisan yang mengandung ungkapan metaforis. Teknik catat digunakan untuk mencatat semua data yang terkumpul dan selanjutnya diklasifikasikan berdasarkan penjenisan metafora oleh Lakoff \& Johnson dan jenis skema citra menurut teori Cruse \& Croft (2004). Selanjutnya mengkaji makna konseptual menggunakan teori Lakoff \& Johnson (2003).

\section{PEMBAHASAN}

Paparan hasil penelitian ini disusun berdasarkan jenis kategori metafora yang ditemukan. Hasil penelitian secara umum menunjukkan bahwa metafora struktural paling banyak ditemukan. Skema citra yang ditemukan dalam metafora sebanyak 4 skema citra, yaitu skema kekuatan/pengendalian atau force/restraint, skema keberadaan/proses atau excistence/process, skema identitas/kesesuaian atau identity/matching, skema keberadaan/objek atau excistence/object. Berikut ini adalah pemaparan hasil analisis metafora struktural, orientasional, dan ontologis yang ditemukan dalam artikel rihlah di majalah Gontor bulan Maret 2014.

\section{Metafora Struktural}

Metafora struktural yaitu sebuah konsep dibentuk secara metaforis dengan menggunakan konsep yang lain. Metafora struktural ini didasarkan pada dua ranah, yaitu ranah sumber dan ranah sasaran. Metafora struktural berdasar pada korelasi sistematis dalam pengalaman sehari-hari.

Berikut ini kalimat dari majalah Gontor segmen rihlah atau jalan-jalan edisi Maret 2014 yang memuat data metafora struktural.

(1) Gunung-gunung menjulang dengan awan putih menghiasi lerengnya tampak gagah bertengger menjaga Magek.

(2) Gunung-gunung menjulang dengan awan putih menghiasi lerengnya tampak gagah bertengger menjaga Magek.

(3) Gunung-gunung menjulang dengan awan putih menghiasi lerengnya tampak gagah bertengger menjaga Magek.

(4) Sajian gulai jengkol dan sajian sambalnya cukup menggoda di restoran ini. 
(5) Jam Gadang memiliki tinggi 26 meter, dengan bulatan jam pada ke empat sisinya. Dibangun tahun 1826 sebagai hadiah dari Ratu Belanda kepada sekretaris kota, Rook Maker, yang memakan biaya 3000 Gulden.

(6) Gunung-gunung menjulang dengan awan putih menghiasi lerengnya tampak gagah bertengger menjaga Magek.

(7) Rumah makan yang mencantolkan embel-embel Padang cukup menjamur.

Pada data (1) kata hias disandingkan dengan awan putih yang sejatinya kata hias memiliki arti leksikal memperelok diri, berhias, dan berdandan. Namun kata tersebut dipinjam dan digunakan secara metaforis hingga memiliki konteks yang sama dengan kata hias yang dilakukan oleh manusia. Adapun kata hias memiliki skema keberadaan yang berkaitan dengan objek. Berdasarkan analisis data di atas, maka makna konseptualnya adalah hiasan.

Pada data (2) menjaga sejatinya digunakan untuk menggambarkan seseorang yang bertugas memantau keamanan dan keselamatan. Namun di kalimat ini kata menjaga dipinjam dan memiliki arti awan putih yang sedang mengawal Magek. Kata menjaga menjadi memiliki makna metaforis, seakan-akan awan putih tersebut mengawal wilayah Magek. Adapun kata menjaga memiliki skema kekuatan yang dikaitkan dengan pengendalian. Berdasarkan analisis data di atas, maka makna konseptualnya adalah pelindung.

Pada data (3) bertengger biasanya dipakai untuk binatang unggas yang dapat hinggap atau berdiam di dahan atau di tangkai. Namun di kalimat ini bertengger dipinjam dan memaknai bahwasanya awan putih berdiam di lereng gunung menjaga Magek, yang sejatinya bertengger adalah berdiam di dahan atau batang pohon. Adapun kata bertengger memiliki skema keberadaan yang berkaitan dengan objek. Berdasarkan analisis data di atas, maka makna konseptualnya adalah dahan.

Pada data (4) kata menggoda selalu digunakan sebagai ajakan atau menarik hati agar berbuat jahat atau dosa. Namun di sini kata menggoda dipinjam agar memiliki arti dan sifat yang sexy, yaitu makanan yang begitu lezat sampai dapat menarik hati seseorang untuk melirik dan makan makanan tersebut. Adapun kata menggoda memiliki skema keberadaan yang berkaitan dengan objek. Berdasarkan analisis data di atas, maka makna konseptualnya adalah rasa makanan.

Tabel 2. Data Metafora Struktural

\begin{tabular}{|c|c|c|c|c|}
\hline No & Makna Konseptual & Ranah Sumber & Ranah Sasaran & Skema Citra \\
\hline 1 & Hiasan & Menghiasi & Lereng & Keberadaan/Objek \\
\hline 2 & Pelindung & Menjaga & Magek & Kekuatan/Pengendalian \\
\hline 3 & Dahan & Bertengger & $\begin{array}{l}\text { Gunung-gunung } \\
\text { dan Awan putih }\end{array}$ & Keberadaan/Objek \\
\hline 4 & Rasa makanan & Menggoda & $\begin{array}{l}\text { Gulai jengkol dan } \\
\text { sambal }\end{array}$ & Keberadaan/Objek \\
\hline 5 & Pengeluaran & Memakan & Biaya & Keberadaan/Objek \\
\hline 6 & Sifat & Gagah & $\begin{array}{l}\text { Gunung-gunung } \\
\text { dan awan }\end{array}$ & Keberadaan/Objek \\
\hline 7 & Terkenal & Menjamur & Rumah makan & Keberadaan/Objek \\
\hline
\end{tabular}


Pada data (5) Pada makna leksikal makan adalah kegiatan memasukkan makanan ke dalam mulut, namun kata memakan di sini dipinjam agar menjadi kata yang memiliki makna metaforis, memakan di sini diungkapkan pembangunan tersebut menghabiskan banyak uang dan diungkapkan hingga seakan-akan bangunan tersebut memakan banyak uang untuk tumbuh. Adapun kata memakan memiliki skema keberadaan yang berkaitan dengan objek. Berdasarkan analisis data di atas, maka makna konseptualnya adalah pengeluaran.

Pada data (6) sifat gagah umumnya dipakai untuk menggambarkan keadaan seseorang atau pria yang kuat dan berbadan tegap. Tetapi adjektiva tersebut dipinjam dan digunakan untuk menggambarkan keadaan lereng gunung yang menjulang dengan kokoh, layaknya pria yang kuat. Kata tersebut berubah makna secara metaforis. Adapun kata menggoda memiliki skema keberadaan yang berkaitan dengan objek. Berdasarkan analisis data di atas, maka makna konseptualnya adalah sifat.

Pada data (7) pada hakikatnya jamur dikenal sebagai spora yang dapat hidup di tempat lembap dan berkoloni. Selain itu, jamur dapat tumbuh dengan cepat dan memiliki sifat yang mengakar. Pada kalimat ini kata menjamur dipinjam agar memiliki arti dan sifat yang sama seperti tanaman jamur yaitu mengakar dan berkembang secara cepat, seakan-akan perkembangan bisnis rumah makan Padang meluaskan teritorial seperti tanaman jamur. Adapun kata menjamur memiliki skema keberadaan yang berkaitan dengan objek. Berdasarkan analisis data di atas, maka makna konseptualnya adalah terkenal.

\section{Metafora Orientasional}

Metafora orientasional berhubungan dengan orientasi pengalaman manusia, seperti naik-turun (up-down), dalam-luar (in-out), depan-belakang (front-back), hidupmati (on-off), dalam-dangkal (deep-shallow), dan pusat-keliling (central-peripheral). Orientasi ruang muncul didasarkan pada pengalaman fisik manusia dalam mengatur orientasi arah dalam kehidupan. Pengalaman itu menyatu dalam pikiran manusia sehingga mengonkretkan hal yang abstrak menjadi nyata. Misalnya, mengonkretkan yang abstrak dengan menggunakan dimensi naik-turun (up-down). Rasa bahagia (happy) dan sedih (sad) dipetakan dalam dimensi naik-turun (up-down). Metafora orientasional merefleksikan konsep spasial yang berbeda-beda menurut pengalaman fisik atau budaya masyarakatnya sehingga fenomena ini ada pada semua bahasa.

Berikut ini kalimat dari majalah Gontor segmen rihlah (jalan-jalan) edisi Maret 2014 yang memuat data metafora orientasional.

(8) Orang Padang menyebutnya sebagai Pasar Atas.

Tabel 3. Data Metafora Orientasional

\begin{tabular}{cllll}
\hline No & Makna Konseptual & Ranah Sumber & Ranah Sasaran & Skema Citra \\
\hline 1 & Kualitas & Atas & Pasar & Identitas/Kesesuaian \\
\hline
\end{tabular}


Pada data (8) kata atas mempunyai makna leksikal, yaitu tempat yang tinggi. Namun di sini kata atas dipinjam dan digunakan olah masyarakat Bukit Tinggi sebagai nama ganti dar Pasar Ateh, untuk menggambarkan keadaan pasar yang menjual barang-barang yang berkualitas baik seakan-akan selalu di atas untuk kualitas. Adapun kata atas memiliki skema identitas yang dikaitkan dengan kesesuaian. Berdasarkan analisis data tersebut, maka makna konseptualnya adalah kualitas.

\section{Metafora Ontologis}

Metafora ontologis adalah metafora yang mengonseptualisasikan pikiran, pengalaman, dan proses hal abstrak lainnya ke sesuatu yang memiliki sifat fisik. Dengan kata lain metafora ontologis menjadikan nomina abstrak sebagai nomina konkret. Metafora ontologis adalah metafora yang melihat kejadian, aktivitas emosi, dan ide sebagai entitas dan substansi.

Berikut ini kalimat dari majalah Gontor segmen rihlah (jalan-jalan) edisi Maret 2014 yang memuat data metafora ontologis.

(9) Tak lengkap rasanya jika di Padang Panjang tidak menikmati kuliner satenya yang legendaris.

(10) Warisan rasa sate yang berkuah kuning kental

(11) Yap Yek adalah seorang Tionghoa pembuat sepatu dengan kualitas jempolan.

Pada data (9) kata legendaris dipinjam dan memiliki arti metaforis terkenal. Kata legendaris dimaknai dan diartikan untuk menyimbolkan seseorang pahlawan atau tokoh terkenal dalam buku. Namun kata legendaris digunakan seakan-akan sate Padang bersifat yang sama seperti tokoh terkenal atau pahlawan. Adapun kata legendaris memiliki skema keberadaan yang berkaitan dengan proses. Berdasarkan analisis data di atas, maka makna konseptualnya adalah terkenal.

Pada data (10) kata warisan sejatinya hanya dapat digunakan untuk menggambarkan barang atau harta pusaka yang diberikan kepada keturunan secara turun temurun sesuai adat yang berlaku. Namun warisan pada data (10) memiliki arti leksikal yang sama namun dipinjam menjadi seakan-akan resep sate yang berkuah kuning kental tersebut harta pusaka yang turun temurun diturunkan ke anak cucunya. Adapun kata warisan memiliki skema identitas yang berkaitan dengan kesesuaian. Berdasarkan analisis data di atas, maka makna konseptualnya adalah turun temurun.

Pada data (11) kata jempolan mempunyai makna metaforis yang berarti bagus, terbaik atau sesuai dengan namanya ibu jari yaitu yang paling atas. Pada data (11) kata jempolan dipinjam dan di sandingkan dengan kata sepatu agar dapat menggambarkan bahwa kualitas pembuatan sepatu yang nomor satu. Adapun kata jempolan memiliki skema keberadaan yang berkaitan dengan proses. Berdasarkan analisis data di atas, maka makna konseptualnya adalah kualitas barang.

\section{Tabel 4. Data Metafora Ontologis}

\begin{tabular}{cllll}
\hline No & Makna Konseptual & Ranah Sumber & Ranah Sasaran & Skema Citra \\
\hline 1 & Terkenal & Legendaris & Sate & Keberadaan/Proses \\
2 & Turun temurun & Warisan & Rasa & Identitas/kesesuaian \\
3 & Kualitas barang & Jempolan & Sepatu & Keberadaan/proses \\
\hline
\end{tabular}




\section{PENUTUP}

Setelah menganalisis jenis-jenis metafora yang terdapat pada majalah Gontor bertema Jalan-jalan, penulis dapat menyimpulkan dari artikel rihlah yang telah dianalisis, serta dari artikel tersebut ditemukan sebanyak 11 data metafora. Berdasarkan hasil analisis sesuai dengan teori Lakoff \& Johnson sebagai teori utama jenis-jenis metafora konseptual ditemukan sebanyak; 7 metafora struktural dengan konsep makna hiasan, pelindung, dahan, rasa makanan, pengeluaran, sifat, dan terkenal; 3 metafora orientasional dengan konsep makna terkenal, turun temurun, dan kualitas barang; dan 1 metafora ontologis dengan konsep makna kualitas. Berdasarkan hasil analisis skema citra dengan teori Cruse \& Croft sebagai ditemukan sebanyak 1 skema force/restraint, 2 skema excistence/process, 2 skema identity/matching, 6 skema exciatence/object.

\section{DAFTAR PUSTAKA}

Arimi, S. (2015). Linguistik Kognitif: Sebuah Pengantar. Yogyakarta: A. Com Advertising.

Croft, W., \& Cruse, D. A. (2004). Cognitive Linguistics. Cambridge: Cambridge University Press.

Cuyckens, G., \& Geeraets. (2012). Introducting Cognitive Linguistics. New York: Oxford University Press.

Dessiliona, T., \& Nur, T. (2018). Metafora Konseptual dalam Lirik Lagu Band Revolverheld Album in Farbe. Sawerigading, 24(2), 177-184. https://doi.org/10.26499/sawer.v24i2.524

Evans, V., \& Green, M. (2006). Cognitive Linguistics. Edinburg: Edinburg University Press Ltd.

Haula, B., \& Nur, T. (2019). Konseptualisasi Metafora dalam Rubrik Opini Kompas: Kajian Semantik Kognitif. RETORIKA: Jurnal Bahasa, Sastra, dan Pengajarannya, 12(1), 25-35. https://doi.org/10.26858/retorika.v12i1.7375

Lakoff, G., \& Johnson, M. (2003). Methaphors We Live By. Chicago: The University of Chicago Press.

Lyra, H. M. (2018). Konseptualisasi Sosiokultural Masyarakat Sunda dalam Metafora Konseptual Bagian Tubuh. Metahumaniora, 8(1), 58-67. https://doi.org/10.24198/mh.v8i1.18874

Moleong, L. J. (2016). Metode Penelitian Kualitatif. Bandung: Remaja Rosdakarya.

Parera, J. D. (2004). Teori Semantik. Jakarta: Erlangga.

Saeed, J. I. (2003). Semantics. Oxford: Blackwell Publisher Ltd.

Sudaryanto. (2015). Metode dan Aneka Teknik Analisis Bahasa. Yogyakarta: Sanata Dharma University Press.

Sugiyono. (2016). Metodologi Penelitian Kuantitatif, Kualitatif, dan R\&D. Bandung: Alfabeta.

Wiradharma, G., \& Tharik WS, A. (2016). Metafora dalam Lirik Lagu Dangdut: Kajian Semantik Kognitif. Arkhais - Jurnal Ilmu Bahasa dan Sastra Indonesia, 7(1), 5-14. https://doi.org/10.21009/ARKHAIS.071.02 